\title{
Stress as Perceived by Nurse Interns at Zagazig University Hospitals
}

\author{
Ebtsam Nabil El Said ${ }^{1 *}$, Sahar Hamdy El Said ${ }^{2}$, Azza Abdeldayem Ata ${ }^{2}$ \\ ${ }^{l}$ M.Sc. Nursing, Faculty of Nursing, Zagazig University, Egypt \\ ${ }^{2}$ Nursing Administration, Faculty of Nursing, Zagazig University, Egypt.
}

*Corresponding Author: Ebtsam Nabil El Said, M.Sc. Nursing, Faculty of Nursing, Zagazig University, Egypt

\begin{abstract}
Background: Nurse Interns is considered stressful for nursing staff at all levels. They need to exhibit more efforts to face the demand of that profession. Physical symptoms of work-related stress are common. Time management can help nurses make stability between their occupational and individual lives more efficiently and effectively. It is important to manage their time to minimize stress for improving the quality of care, and to reduce physical complaints).
\end{abstract}

The Aim: of the present study was conducted to assess stress as perceived by nurse interns at zagazig university hospitals.

Survey Design: A Descriptive design was employed to convey the present study,

Study Setting: in the different clinical areas of Zagazig University Hospitals where the nurse interns practice their training in the academic year 2017- 2018.

The Sample: included all nurse interns $(n=118)$.

One Tool: Perceived Stress Scale was used to collect the data.

Results: all nurse interns (100\%) had high level of stress, there is a statistically significant difference between the total mean score of stress among nurse interns \& there is a statistically significant relation between nurse intern's stress score and all personal characteristics except marital status

Conclude: all nurse interns (100\%) had high level of stress, and the highest mean score of stress was related to lack of knowledge and skills, while the lowest mean score was related to clinical environment. It is

Recommended: that design \& implement stress management programs for nursing students. It should aim to educate students nurse with better stress management skill\& faculty members should emphasize participation in stress coping programs to improve academic performance of nurse students.

Keywords: Stress, Stressors, Nurse Interns, internship year

\section{INTRODUCTION}

The nursing internship year is the final clinical year, where students are exposed to the direct clinical experience of patient care in a healthcare setting and is part of the degree requirements. Clinical experiences include the rotation of nursing interns through various clinical setting for 12 months. These clinical settings include Pediatric (Medical-Surgical), Adult (Medical-Surgical), Critical Care (Pediatric-Neonatal, Adult-Medical, AdultSurgical), Operation Room, Emergency Room, Dialysis (Hemodialysis, Peritoneal), Obstetrics, Gynecology, Labor and Delivery, and Endoscopy (AlThiga et al., 2017).
The internship year is a transitional stage for a nurse to complete work responsibilities from educational experience. Becoming a registered nurse in the future is a crucial step. Nurse interns learn through direct patient care and familiarization with new skills. Nurse interns fulfill the responsibilities of head nurses as part of their internship training immediately after graduation. They are thus exposed to a threatening situation where different variables are to be controlled and manipulated (Mabrou, 2013; Henderson, 2014).

The term intern refers to a nurse in the "first stage of their career, recently graduated from university and between the transitional phase of 
student and qualified nurse" (St Clair , 2013). The internship period is a transitional phase for intern-nurses to learn and equip themselves for a demanding career ahead. Intern-nurses usually perceive their first year of clinical practice as a time of significant stress curtailing from fears of harming a patient , medication errors, litigation ,unpreparedness, medical emergency and coping in unpredictable situation"(Missen et al., 2014).

It is the responsibility of the nurse interns to maintain the current high level of relevant knowledge and skills. By remaining professionally growing and remaining current in their individual practice areas, they can develop expert power. Practice in nursing and care technologies are moving at an ever-increasing rate. Considering the benefits of continuing education, going to conferences and seminars and seeking additional formal education are all ways of fleshing out an expert power (Harris et al., 2009).

Stress is the pattern of both specific and nonspecific responses that an organism makes to stimulus and/or events that disturb its equilibrium and exceed its ability to cope (Sharma et al., 2013).Stress is a complex event that happens in the interaction between individuals and their inner and outer environments; such reciprocal interaction can cause physical, mental, emotional, and behavioral changes (Griffin, 2014).

Sources of stress among nurse intern include difficulty in developing relationships with professionals, lack of familiarity with operating procedures and with the hospital environment, lack of professional proficiency, committing errors, uncertainty of patients' expectations, use of improper clinical teaching methods, complexity of the working environment, lack of familiarity with the regulations of the hospital and learning incompetence, communicate ineffectively with patients and their families, lack of knowledge and confidence to give patients safe and independent care, fear of setting medical apparatus, inability to carry out the procedure of machines or tests, dealing with ambiguous orders, unfamiliar diagnosis or order which not experiencing before (Jamshidi et al., 2016).

Sources of stress during training include; fear from unknown, new clinical environment, conflict between the ideal and real during the clinical practice, unfamiliarity with medical history, lack of professional nursing skills, unfamiliar patient' diagnosis and therapeutic modalities. Also the nurse intern students' had to provide physiological, psychological and social care to critically ill patients with their fear of making mistakes or dying of terminally ill patients, also, negative interaction with instructors, continuous observation by instructors and unpunctuality, poor relationships with hospital staff, and sometimes even talking with other health care providers. Moreover, stress in nurse intern students may arise from a combination of personal and extracurricular factors rather than from the educational program itself (Shalaby \& AlDilh, 2015).

Stress may result in positive or negative outcomes. Behavioral, psychological, or medical may have negative consequences. For example, behavioral stress can lead to harmful or detrimental actions such as smoking, alcohol or abuse of drugs, and overeating. Other behaviors caused by stress are proneness to accidents, violence towards oneself or others, and disorders of appetite. The psychological consequences of stress can interfere with the mental health and well-being of an individual. Sleep disturbances, depression, family issues, and sexual dysfunction are problems(Richy \& Griffin, 2016).

Managing stress involves three steps 1) identifying stressors. 2) Determining the consequences of stress, 3) planning to eliminate or reduce stress. Working pressure and the lack of time to complete jobs are one of the stressors in the work environment. For example, one of the stressful work-related situations is that, on the one hand, individuals are placed under the burden of requests or high pressure in the work environment, and, on the other hand, that individual would be given a limited time to fulfill these requests, and it is natural that because he cannot afford to do so, he will be confronted with other people's consecutive objections (Abbasnejad, Farahani \& Nakhaei , 2013).

\subsection{Significance}

Nurse interns are baccalaureate nursing students who, through an internship training program, begin the role transition from senior to professional nurse. The transition from student to qualified nurse is a stressful experience due to the increased responsibility and accountability of the newly graduated nurse. (Abdelsalam et al, 2016). Nurse interns in clinical training face a dichotomy of experiences related to student 
engagement. They are often torn between feelings of excitement to finally put theory into practice and utter fear of the dynamic and unpredictable clinical environment they are about to enter. It has been well documented that clinical internships are a source of increased stress. In general, healthcare professionals experience more stress-related health issues than professionals not in healthcare. Therefore, the purpose of this study is to assess stress as perceived by nurse interns at zagazig university hospitals.

\subsection{Aim}

Assess the stress as perceived by nurse interns at zagazig university hospitals.

\subsection{Research Questions}

What is the stress level among nurse interns?

\section{Methodology}

\subsection{Design}

Descriptive design was used to achieve the aim of the study.

\subsection{Setting}

The study was conducted in the different clinical areas of Zagazig University Hospitals where the nurse interns practice their training in the academic year 2017- 2018 which included Intensive Care Unit(ICU), operating room, dialysis unit, cardio care unit, medical unit, surgical unit, incubator, pediatric unit, obstetric \& genealogical unit, and labor room. Zagazig Hospitals consisted of two sectors the first is the emergency sector and the second is El-Salam sector.

\subsection{Subjects}

The sample of the study included all nurse interns who succeeded in the academic year 2017-2018, and practiced their internship year at Zagazig University Hospitals $(n=118)$. The total number of nurse interns were 491 nurse interns from which 373 of them spend their internship according to their residence and the remaining numbers was 118 practicing their internship year at Zagazig University Hospitals.

\subsubsection{Reliability of Data Collection Tools}

\begin{tabular}{|l|l|}
\hline Name of tool & No of items \\
\hline Perceived stress scale & 29 \\
\hline 2.6. Field Work &
\end{tabular}

The data collection phase of the study lasted long two months from the beginning of March

\subsection{Instruments}

\subsubsection{Perceived Stress Scale (PSS) (Appendix III)}

Perceived stress scale developed by Sheu et al. (1997) in order to assess nurse interns' stress level and type of stressors. It consisted of 29 items grouped into six domains related to the sources of stress as Stress from taking care of patients (8), Stress from assignments and workload (5), Stress from lack of professional knowledge and skills (3), Stress from lack of professional knowledge and skills(3), Stress from peers and daily life(4), Stress from instructors and nursing staff(5).

\subsubsection{The Scoring System}

The responses of nurse interns stress, used five point Likert scale ranged from never (0), rarely(1), sometimes(2), often(3), always(4), the total score of all domains was calculated and converted into percent score by dividing the nurse interns total score by the maximum possible score then multiply by $100 \%$.

- If the score was $33,3 \%$ or less it referred to the low level of stress.

- Average if level of stress range from $33,4 \%$ $-66,5 \%$.

- High if level of stress was more than 66, 5\% (soliman, 2009 and Atia, 2007).

\subsection{Validity and reliability}

\subsubsection{Validity}

The tools of data collection were tested for their content and face validity sheet by a jury of five experts from which 3 assistant professor of nursing administration, 2 professors of community health nursing at the faculty of nursing at Zagazig University. The face \&content validity sheet involved two parts. The first part: included the opinions of the experts for each item that were recorded on a two point scale: relevant, and not relevant. The second part: covered general or overall opinion about the form which expressed their opinions and comments on the tools for clarity, applicability, comprehensiveness, understanding, any suggestions for any additional or omissions of items and ease of implementation. According to their opinions all recommended modifications were performed by the researcher. 
researcher to elicit their opinions. The purpose of the study was explained to the participated students and ways to fill in the questionnaire sheets. They were completed in the same time of distribution and took about 20-30 minutes. The researcher checked each questionnaire sheet after they had been completed to ensure the completion of all information. The researcher met nurse interns students three times weekly in their different clinical setting. The researcher collected data by herself.

\subsection{Pilot Study}

A pilot study was carried out with $10 \%$ of the study sample (12) nurse interns to test the tools feasibility, understandability and to estimate the time consumed for filling in the forms. A brief explanation of the purpose of the study was provided to every participant in the pilot study, and then they were provided with a copy of the study tools. The time consumed in answering the questions was about 20-30 minutes for each tool. Data collected from the pilot study was reviewed and no modifications to items of the tools so the nurse interns included in the main study sample.

\subsection{Ethical Considerations}

The study was approved by the Ethics reasearch Committee at the Faculty of Nursing; Zagazig University. The verbal explanation of the nature, purpose, and benefits of the study was performed by the researcher to nurse interns included in the study sample. Oral and written consent were taken from subjects and reassured them about confidentiality and anonymity of the study. They were informed about their right to refuse or withdraw from the study at any time without giving a reason.

\subsection{Statistical Design}

Data entry and statistical analysis were performed using computer software, the statistical package for social sciences (SPSS), version 20. Suitable descriptive statistics were used such as; frequency, percentage, mean and standard deviation. The chi - square test was used to detect the relation between the quantitative variables. In addition, correlation coefficient (r) test was used to estimate the close association between variables. $\mathrm{P}$-values which were less than $0.05,0.001$ were considered as statistically significant and highly significant respectively. The given graphs were constructed using Microsoft Excel software.

\section{ReSUlts}

Table 1shows personal characteristics of nurse interns, it's clear from the table that, near from the half of nurse interns were in the age group23 years old $(49,2)$, with mean age 23.07 years. The highest percentages of nurse interns were female, married, and didn't attend any previous training program about stress management $(82.2 \%, 61.9 \%$, and $94.1 \%$ respectively).

Table2 Shows the mean score of nurse intern's stress dimensions. It's clear from the table there is a statistically significant difference between the total mean score of stress among nurse interns $(\mathrm{p}<0.5)$.

Table3 Nurse intern's stress shows that all nurse interns $(100 \%)$ had high level of stress and the highest mean score are related to lack knowledge and skills, while the lowest mean score of stress are related to clinical environment .

Table4 shows relation between nurse intern's stress level and personal characteristics. It's clear from the table that there is a statistically significant relation between nurse intern's stress score and all personal characteristics except marital status $(\mathrm{P}<.05)$.

\section{DISCUSSION}

\subsection{Personal Characteristics of the Nurse Interns}

The findings of the present study indicated that the highest percentages of the nurse interns were female, married, had the mean age of 23 years, and not attend any previous training program about stress management. It may due to lack of courses and workshop regarding stress management and the nursing occupation is feminists this gives the explanation for this result.

This findings were agreement with a study Carried out at Faculty of Nursing, Benha university by Abdullah(2014) who assess the effect of stress management educational program for newly baccalaureate graduate nurses on their productivity and found that the highest percentages of the nurse interns were female, married, had the mean age of 23 years, and not attend any previous training program about stress management. Also the study conducted at Beni Sweif university hospital by Elsayed (2015) who found that all of nurse interns not got any training. Again, these findings go in line with a study in Peshawar by Said et al. (2015) who found that almost all of 
the student nurses have not got any previous training

\subsection{Stress score}

The findings of the present study indicated that there is a statistically significant difference in all dimensions and the total score of stress among nurse interns. All nurse interns had a high level of stress. The high level of stress was caused by; nurse interns worry about successes in completing the internship training program, engagement in patient care and expose to a new setting, as well as, they spend a substantial time in the clinical areas, with the heavy responsibility of being accountable for patients as a result of the shortage in nurses staff, some student can't cope with their stressors because they don't have the suitable study plan, in addition to the nurse interns face the problems of organization routine and work practice responsibility.

This finding was consistent with the results of the study conducted at Malaysia by Gibbons et al., (2011) who investigated the factors that influence the academic performance in the clinical year students of Universiti Kebangsaan and found that the nursing students had a high level of stress during their clinical years. Also many previous studies found that nursing student have high level of stress (Goff, 2011; Reeve et al., 2013).

While this finding contradicted with the study conducted at Saudi Arabia by Shdaifat et al, (2018) who assess the level of stress and common stressors among nursing students and found that the nursing students experience a moderate level of stress.

Regarding the stress dimensions, the results of the present study shows that the highest mean score of the stress was caused by lack of knowledge and skills as reported by intern nurses, this may be due the nurse interns are unfamiliar with medical history and terms , professional nursing skills, patients' diagnoses and treatments, and unclear clinical guidelines and policies. In addition to , the nurse interns joint the training internship program in between the ages of 22-23 years, and are then faced with some patient care responsibilities for which they lack the prerequisite professional knowledge and skills, which is the root of the stress they face in addition to the .

The finding of the current study was consistent with the results of the study conducted at Saudi Arabia by Ismaile (2016) who determine stressors types and degrees during two clinical periods among nursing students and found that the highest mean score of the stress was caused by lack of knowledge and skills as reported by intern nurses. Also the study conducted by Shdaifat et al,(2018) who found that the highest mean score of the stress was caused by lack of knowledge and skills among nursing students before program implementation and this mean decrease after implementation of the program.

Clinical practice in nursing is essential to train students to be professional nurses through applying academic skills in practice, helping bridge the theory-practice gap that commonly faces newly qualified nurses (Labrague, 2014).

The findings of the current study reveals that the lowest mean score of the stress dimensions was related to clinical environment as reported by nurse interns. The lowest score may be due the nurse interns generally undertake basic courses for clinical practice in the hospital from the beginning of the educational program,

thus they face this great escalation, in addition to the application of new techniques for patients, relationship with different patients, fear of making mistakes due to inadequate experience and evaluation of preceptors, cause nurse interns to experience stress from clinical environment.

Nurse interns stressors in the clinical setting reported included; making an error and harming patients, limited knowledge and skills for practice and difficulties interacting with the other healthcare providers in the clinical setting and unfamiliar clinical areas.

As well as, the different between the skills and theoretical knowledge that the nurse interns learnt from the lectures in their pre-clinical years and clinical internship year. The knowledge and experiences are different as the time goes by and these aspects will affect the confidence level of the students in their clinic practice. Therefore, these combining aspects may become factors that can contribute to experience nurse interns with stress from clinical environment.

In this respect the study conducted by Kaur et al., (2009) who found the clinical environments were not welcoming the nurse interns and consider the main cause of stress.The finding of the current study was consistent with the results of the study of Reeve et al., (2013) who found that the lowest mean score of the nurse interns stress was related to clinical environment 
- Again the study conducted at by Eswi et al,(2013)who found that the mean score of the nurse interns stress was related to clinical environment . Also the study of Collins (2015) who found that the lowest mean score of the stress dimensions among nursing students was related to clinical environment before program implementation and this mean decrease after implementation of the program . And the study conducted at Saudi Arabia by Ismaile, (2016) who found that the nursing students in Saudi Arabia faces stress from their clinical environment .

\section{CONCLUSION}

Based on the study finding, it could be concluded that:

All nurse interns $(100 \%)$ had high level of stress, there is a statistically significant difference between the total mean score of stress among nurse interns \& there is a statistically significant relation between nurse intern's stress score and all personal characteristics except marital status, and the highest mean score of stress was related to lack of knowledge and

Table1: Personal characteristics of nurse interns $(n=118)$ skills, while the lowest mean score was related to clinical environment.

\section{RECOMMENDATIONS}

6.1. In The Light of the Study Findings, the Following Recommendations can be Proposed

- Design \& implement stress management programs for nursing students. It should aim to educate students nurse with better stress management skill.

- Faculty members should emphasize participation in stress coping programs to improve academic performance of nurse students.

\subsection{Further Researches about}

- Replication of the study in other universities is highly recommended to achieve generalization results.

- Investigate factors that affect nurses' interns' managerial skills acquisition at the clinical setting.

\begin{tabular}{|c|c|c|}
\hline \multirow[b]{2}{*}{ Personal Characteristics } & \multicolumn{2}{|c|}{$(\mathrm{N}=118)$} \\
\hline & No & $\%$ \\
\hline \multicolumn{3}{|l|}{ Age in year } \\
\hline 22 & 26 & 22.0 \\
\hline 23 & 58 & 49.2 \\
\hline 24 & 34 & 28.8 \\
\hline Mean +SD & \multicolumn{2}{|c|}{$23.0720 \pm 0.70794$} \\
\hline \multicolumn{3}{|l|}{ Gender } \\
\hline Male & 21 & $17.8 \%$ \\
\hline Female & 97 & $82.2 \%$ \\
\hline \multicolumn{3}{|l|}{ Marital status } \\
\hline Single & 45 & $38.1 \%$ \\
\hline Married & 73 & $61.9 \%$ \\
\hline \multicolumn{3}{|c|}{ Attend previous training program about stress management } \\
\hline Yes & 7 & $5.9 \%$ \\
\hline No & 111 & $94.1 \%$ \\
\hline
\end{tabular}

Table2: Mean scores of Nurse Intern's stress dimensions $(n=118)$

\begin{tabular}{|l|l|l|l|l|l|}
\hline \multicolumn{2}{|l|}{ Practice } & \multicolumn{2}{l|}{} & Independent t test & P value \\
\hline 1. Taking care of patient & 2.6551 & \pm & 3.9452 & $-8.755-$ & .000 \\
\hline 2. Assignment \& Workload & 2.5102 & \pm & 3.7373 & $-5.364-$ & .000 \\
\hline 3. Lack of knowledge and skills & 2.7373 & \pm & 3.4237 & $-8.436-$ & .000 \\
\hline 4. Clinical environment & 2.3531 & \pm & 3.4011 & $-10.968-$ & .000 \\
\hline 5. Peers \& Daily life & 2.5275 & \pm & 3.6822 & $-12.032-$ & .000 \\
\hline 6. Taking care of patient & 2.5498 & \pm & 3.8369 & $-9.461-$ & .000 \\
\hline Total stress & 2.5555 & \pm & 3.6711 & .000 & \\
\hline
\end{tabular}

*Statistically significant at $P<.05$

Table3: Nurse Intern's stress levels $(n=118)$

\begin{tabular}{|l|l|l|l|}
\hline \multicolumn{2}{|l|}{} & Pre \\
\cline { 3 - 4 } \multicolumn{2}{|l|}{ Levels of stress } & $\mathbf{N}$ & $\%$ \\
\hline & Low & 0 & $0.0 \%$ \\
\cline { 3 - 4 } & Average & 0 & $0.0 \%$ \\
\hline
\end{tabular}




\begin{tabular}{|l|l|l|}
\hline High & 13 & $100.0 \%$ \\
\hline
\end{tabular}

*Statistically significant at $p<0.05$

Table4: Relation between nurse intern's stress score and their personal characteristics $(n=118)$

\begin{tabular}{|c|c|c|c|c|c|c|c|c|c|}
\hline & \multicolumn{6}{|c|}{ Stress level } & \multirow[t]{3}{*}{ Chi square } & \multirow[t]{3}{*}{ Sign } \\
\hline & & \multicolumn{2}{|c|}{ High } & \multicolumn{2}{|c|}{ Average } & \multicolumn{2}{|c|}{ Low } & & \\
\hline & & $\mathrm{N}$ & $\%$ & $\mathrm{~N}$ & $\%$ & $\mathrm{~N}$ & $\%$ & & \\
\hline \multirow[t]{2}{*}{ Gender } & Female & 46 & $100.0 \%$ & 44 & $67.7 \%$ & 7 & $100.0 \%$ & \multirow[t]{2}{*}{20.830} & \multirow[t]{2}{*}{0.000} \\
\hline & Male & 0 & $0.0 \%$ & 21 & $32.3 \%$ & 0 & $0.0 \%$ & & \\
\hline \multirow[t]{2}{*}{ Marital status } & Married & 24 & $52.2 \%$ & 21 & $32.3 \%$ & 0 & $0.0 \%$ & \multirow[t]{2}{*}{9.093} & \multirow[t]{2}{*}{0.011} \\
\hline & Unmarried & 22 & $47.8 \%$ & 44 & $67.7 \%$ & 7 & $100.0 \%$ & & \\
\hline \multirow[t]{2}{*}{ Training } & Yes & 0 & $0.0 \%$ & 7 & $10.8 \%$ & 0 & $0.0 \%$ & \multirow[t]{2}{*}{6.068} & \multirow[t]{2}{*}{0.048} \\
\hline & No & 46 & $100.0 \%$ & 58 & $89.2 \%$ & 7 & $100.0 \%$ & & \\
\hline \multirow[t]{3}{*}{ Age } & 22 & 0 & $0.0 \%$ & 29 & $44.6 \%$ & 0 & $0.0 \%$ & \multirow[t]{3}{*}{47.150} & \multirow[t]{3}{*}{0.000} \\
\hline & 23 & 22 & $47.8 \%$ & 29 & $44.6 \%$ & 7 & $100.0 \%$ & & \\
\hline & 24 & 24 & $52.2 \%$ & 7 & $10.8 \%$ & 0 & $0.0 \%$ & & \\
\hline
\end{tabular}

*Statistically significant at $P<.05$

\section{REFERENCES}

[1] AlThiga, H., Mohidin, S., Park, Y. S., \& Tekian, A. (2017). Preparing for practice: Nursing intern and faculty perceptions on clinical experiences. Medical teacher, 39(sup1), S55-S62.

[2] Mabrou, L. (2013). Nursing management: Approach of Scheduling. Retrieved from: http://www.nursing management.com.

[3] Henderson, H. (2014): Cyclic time scheduling and Block time scheduling. Journal of Nursing Management, 17(9), 15-22.

[4] St Clair, M. B. (2013). New graduate nurses ' experiences of transition during orientation into critical care.

[5] Missen, K., McKenna, L., \& Beauchamp, A. (2014). Graduate nurse program coordinators' perceptions of role adaptation experienced by new nursing graduates: A descriptive qualitative approach. Journal of Nursing Education and Practice, 4(12), 134.

[6] Harris, K. J., Wheeler, A. R., \& Kacmar, K. M. (2009). Leader-member exchange and empowerment: Direct and interactive effects on job satisfaction, turnover intentions, and performance. The Leadership Quarterly, 20(3), 371-382.

[7] Shalaby, S. A. M., \& AlDilh, S. M. S. (2015). Exploring the Relationship between Perceived Stress and Academic Achievement among Critical Care Nursing Students. Athens Journal of Health, 2(4), 283-296.

[8] Sharma, B., Prasad, S., Pandey, R., Singh, J., Sodhi, K. S., \& Wadhwa, D. (2013). Evaluation of Stress among Post-graduate Medical and Dental Students: A pilot study. Delhi Psychiatry Journal, 16(2), 312-316.

[9] Sharma, M., \& Jagdev, T. (2011). Use of music therapy for enhancing self-esteem among academically stressed adolescents. Pakistan
Journal of Psychological Research,27(1), pp53.

[10] Griffin, C. 2014. Department of Maternal and Fetal Medicine, King Edward Memorial Hospital, Subiaco, WA, Australia Accepted 27 May 2014. DOI, 10, 1471-0528.

[11] Richy W.Griffin (2016):Fundmental of management ,eighth Ed ,ch9,P.p(273-279), canda.

[12] Jamshidi, N., Molazem, Z., Sharif, F., Torabizadeh, C., \& Najafi Kalyani, M. (2016). The challenges of nursing students in the clinical learning environment: A qualitative study. The Scientific World Journal, 2016.

[13] Abbasnejad, E., Farahani, A., \& Nakhaei, A. (2013). The relationship between time management and job stress in teachers of physical education and non physical education.Advances in Environmental Biology, 1340-1348.

[14] Abdelsalam, G., Basal, A. A., Ebrahem, R. A., \& Elnagar, S. A. (2016). Perceptions of role transition among nursing interns at Tanta University. J Nurs Health Sci, 5, 16-22.

[15] Sheu, S., Lin, H. S., Hwang, S. L., Yu, P. J., Hu, W. Y., \& Lou, M. (1997). The development and testing of perceived stress scale of clinical practice. Nursing Research (Republic of China), 5(4), 341-351.

[16] Soliman, M. (2009): The effect of training on head nurses time management skills at Benha University and Benha Teaching Hospitals, unpublished Doctorate Thesis in Nursing Administration, Faculty of Nursing, Benha University.

[17] Ismaile, S. (2016) Stressors' and Coping Strategies among Saudi Nursing Students' in Their Clinical Practice. HealthMed Journal , 10, 25-32.

[18] Abdulla N A (2014): The Effect of Time Management Educational Program for Newly 
Baccalaureate Graduate Nurses on Their Productivity. Doctorate Degree. Faculty of Nursing, Benha University.

[19] El-Sayed , N. (2015): Enhancing Nurse Intern's Knowledge And Practice in internal disaster management at Benha and Bany Swaif hospital - Unpublished Doctorate Thesis, Faculty of Nursing, El Benha University. Egypt. Retrieved on January 6, 2015, from: main. Eulc .Edu.eg/eulc_v5/Libraries/.../BrowseThesis Pages. Aspx? fn

[20] Said, A.B., Ulf at, S., Shaheen, R. And, Riaz, R. (2015): Knowledge, Attitude and Practice of Nurses Regarding Disaster Management: A Study from Peshawar KPK. International journal of endorsing health science research .Vol.3.Issue 3.Pp .12-14.

[21] Gibbons, C., Dempster, M., \& Moutray, M. (2011). Stress, coping and satisfaction in nursing students. Journal of advanced nursing, 67(3), 621-632.

[22] Goff, A. M. (2011). Stressors, academic performance, and learned resourcefulness in baccalaureate nursing students.International journal of nursing education scholarship, 8(1).

[23] Reeve, K. L., Shumaker, C. J., Yearwood, E. L., Crowell, N. A., \& Riley, J. B. (2013). Perceived stress and social support in undergraduate nursing students' educational experiences. Nurse education today, 33(4), 419-424.

[24] Shdaifat E, Jamama A , \& Al-Amer M (2018): Stress and Coping Strategies Among Nursing Students. Global Journal of Health Science; Vol. 10, No. 5, 33-41.
[25] Ismaile, S. (2016) Stressors' and Coping Strategies among Saudi Nursing Students' in Their Clinical Practice. HealthMed Journal , 10, 25-32.

[26] Labrague, L. J. (2014). Stress, stressors, and stress responses of student nurses in a government nursing school.

[27] Kaur, S., Das, K., Amrinder, N., Kanika, S., Meena, P., Gagandeep, I., \& Arash, R. (2009). Stress and coping in the

[28] Reeve, K. L., Shumaker, C. J., Yearwood, E. L., Crowell, N. A., \& Riley, J. B. (2013). Perceived stress and social support in undergraduate nursing students' educational experiences. Nurse education today,33(4), 419-424.

[29] Eswi, A. S., Radi, S., \& Youssri, H. (2013). Stress/stressors as perceived by baccalaureate Saudi nursing students. Middle-East Journal of Scientific Research, 14(2), 193-202.

[30] Collins, A M (2015): Effect of two stress management intervention on nurse students perceived stress and general self efficacy., Doctor thesis, Faculty of Nursing, Wayne State University.

[31] Collins, M.D. (2013): Understanding the relationships between leader- member exchange (LMX), psychological empowerment, job satisfaction and turnover intent in a limitedservice restaurant environment. Doctoral Dissertation, Ohio State University, Ohio. Dissertation Abstract International, 68(04) (UMI No: AAT 3260704).com. Updated August 14, 2017. livestrong.com/ article/ 158 633

Citation: Ebtsam Nabil El Said, Sahar Hamdy El Said, Azza Abdeldayem Ata. Stress as Perceived by Nurse Interns at Zagazig University Hospitals. ARC Journal of Nursing and Healthcare. 2020; 6(2):1-08. DOI: doi.org/ 10.20431/2455-4324.0602001.

Copyright: (C) 2020 Authors. This is an open-access article distributed under the terms of the Creative Commons Attribution License, which permits unrestricted use, distribution, and reproduction in any medium, provided the original author and source are credited. 